\title{
Espremeram tudo! Modernidade e tradição na memória de um ex-funcionário da Companhia Vale do Rio Doce
}

\author{
André R. V. V. Pereira*
}

\section{Introdução}

Este trabalho se propóe a discutir o início do processo de disciplinarização da mão de obra na Companhia Vale do Rio Doce (CVRD). Para tanto, recorre à análise de uma entrevista realizada com um ex-funcionário da empresa, que foi criada em 1942, a partir da estatização de uma entidade privada, com o objetivo de extrair, transportar e embarcar para o exterior uma grande quantidade de minério de ferro.

Em seu estudo sobre a Vale, Marta Zorzal e Silva (2004) analisa a posição de destaque ocupada pela empresa na transição para o capitalismo no Brasil. Para a autora, o Estado desenvolvimentista - conceito que orientou essa transição - foi um tipo de arranjo institucional que permitiu que certas atividades e setores comandados pelo poder público fossem mantidos afastados da influência de forças sociais tradicionais. A Vale foi uma das empresas estatais preservadas de tais influências. Além disso, a firma desenvolveu habilidades próprias de planejamento e elaboração de propostas, adquirindo um grau razoável de autonomia com relação ao núcleo duro de decisões do governo federal.

* Doutor em Ciência Política pelo Instituto Universitário de Pesquisas do Rio de Janeiro (IUPERJ). Professor adjunto do Departamento de História da Universidade Federal do Espírito Santo (UFES). 
Sem discordar da autora, é interessante perceber que ela focaliza um dos aspectos do que aconteceu com a CVRD, particularmente no plano de interações com o poder público e com o mercado internacional. Todavia, outra arena foi igualmente relevante: a da relação entre aqueles que ocuparam cargos de gerência e os empregados. O sucesso da empresa também se deveu à disciplinarização dos seus funcionários, tanto em termos de rotinas de trabalho quanto de ação organizacional autônoma. Neste caso, mais especificamente, por meio da eliminação de um foco de mobilização comandado pelo Partido Comunista do Brasil (PCB). Também fez parte de tal estratégia de poder a constituição de uma mitologia em torno da empresa como excelente local para trabalhar, com salários altos, variados benefícios, segurança no emprego etc. ${ }^{1}$

Ao fim de um processo que durou alguns anos, a imagem pública da CVRD passou a ser muito positiva. Essa mitologia ignorou as difíceis condições vividas pelos empregados, com destaque para os acidentes de trabalho e os baixos níveis salariais que prevaleceram no início. Ela apagou a memória de uma greve conduzida pelo PCB na empresa em 1948 e o clima tenso que prevaleceu posteriormente, com várias ameaças de outras paralisações. A cada uma delas, autoridades da Vale e da Delegacia Regional do Trabalho no Espírito Santo reagiam, intensificando a perseguição a lideranças "negativas" e buscando garantir ganhos, como aumentos pontuais, para impedir novas mobilizações. ${ }^{2}$ Durante os anos 1950, os empregados que foram demitidos por conta da greve de 1948 tentaram, pela via individual ou coletiva (junto ao Sindicato dos Ferroviários), a readmissão nos quadros da empresa, no que não foram bem-sucedidos. ${ }^{3} \mathrm{Ou}$ seja, criou-se uma imagem e uma memória da relação entre empresa e empregado. Como toda memória, esta selecionou e deu sentido a algumas lembranças, enquanto eliminou outras - neste caso, tudo o que pudesse se referir a uma postura de questionamento das condições de trabalho, em termos coletivos e com base na noção de direitos universais. Além disso, tendo em vista a importância da empresa na industrialização do Espírito Santo, o processo como um todo impediu que o núcleo da classe trabalhadora capixaba, formado originalmente

1 Nos dois sentidos, ela reproduziu experiências semelhantes, por exemplo, ao caso da Fábrica Nacional de Motores (Ramalho, 1989).

2 Isso pode ser demonstrado pela leitura da pasta do Sindicato dos Ferroviários que consta da documentação do DOPS/ES no Arquivo Público do Estado do Espírito Santo.

3 Fontes disponíveis: 1) o jornal Folha Capixaba, do PCB/ES, em microfilme no Arquivo Público do Estado do Espírito Santo; 2) as circulares do tráfego, que eram documentos internos da CVRD, disponíveis no Centro de Memória da Estrada de Ferro Vitória-Minas, no Museu Vale, em Vila Velha. 
pelos ferroviários da Vale, adquirisse uma identidade e um grau de autonomia que criassem condições para oferecer base de apoio a projetos autônomos de ação coletiva, seja no sindicalismo, seja no plano partidário. ${ }^{4}$

Retomando o argumento inicial, o estudo de caso da Vale mostra que o que de fato se deu foi uma combinação de repressão política com o uso alternado de formas modernas e tradicionais de relacionamento entre a gerência e os empregados. Este trabalho discute as razões que levaram a tal resultado. A leitura da documentação interna da empresa permite identificar a conformação de tal estratégia; contudo, a análise da memória é relevante para testar hipóteses acerca da influência de fatores de tipo estrutural e conjuntural no fenômeno em questão. Para tanto, fez-se uso de uma entrevista concedida por um ex-funcionário da CVRD.

A técnica utilizada foi a de história de vida, direcionada para hipóteses específicas a partir do ponto em que o curso da vida do indivíduo passa a tocar no objeto de pesquisa. Esse procedimento permite fazer uma avaliação do perfil do entrevistado e das formas de inserção da pessoa nas coletividades das quais fez parte. Dessa forma, é possível isolar as idiossincrasias, que não são relevantes para a compreensão do fenômeno em estudo, dos aspectos mais gerais. Tal resultado será obtido da seguinte forma: primeiro, será apresentada a biografia do entrevistado; em seguida, será feita uma avaliação de seu perfil e das formas de inserção social que vivenciou; por fim, será feita a análise da entrevista com base nas percepções do entrevistado a respeito de sua época. Tais percepções correspondem à forma como o indivíduo em questão se posicionou relativamente aos discursos e práticas de poder que se confrontavam (aspectos conjunturais), em uma sociedade tradicional que iniciava um processo de modernização (aspectos estruturais).

\section{Escolhas interpretativas}

Antes de proceder à análise da entrevista, cabe esclarecer quais as opções feitas neste trabalho. Tendo em vista as definições do que seja história oral, minha alternativa é a de concebê-la como metodologia (Ferreira; Amado, 1996), e não como técnica ou disciplina. Conforme foi observado acima, há

4 Efeitos semelhantes foram identificados por Maria Cecília Minayo (2004) no que concerne à atividade da empresa em Minas Gerais. 
um problema a ser discutido, que é o processo disciplinarização da mão de obra. Para tanto, várias fontes vêm sendo consultadas, como jornais, documentos internos da CVRD, fichas do DOPS/ES e entrevistas.

A hipótese principal já foi anunciada: a empresa usou uma combinação de repressão política com o uso alternado de formas modernas e tradicionais de relacionamento entre a gerência e os empregados - as demandas, assim, eram processadas de forma individual e não coletiva. Parte-se também do princípio de que os empregados refletiam sobre as possibilidades que estavam disponíveis e realizavam um cálculo, fazendo opções que lhes pareciam as mais interessantes nas circunstâncias. Para demonstrar tais hipóteses, algumas entrevistas têm sido feitas ${ }^{5}$ - aqui será considerada, em particular, uma delas. A preparação para sua execução foi similar ao tipo de proposta seguida pelo CPDOC/RJ (Alberti, 2004). Todavia, ao contrário dessa linha, que prima pela técnica da história de vida sem pressupostos gerais, a minha escolha foi diferente.

À semelhança do tipo de preocupação revelado por Paul Thompson (1992) quando discute a percepção social dos fatos (p. 145), o que eu busco nos entrevistados é o entendimento que tiveram dos eventos na época. Para tanto, é preciso fazer uma distinção entre a memória que eles elaboraram após os acontecimentos e aquela que, a princípio, está disponível quando respondem às primeiras perguntas gerais que lhes são colocadas. Não cabe aqui fazer uma ampla discussão sobre os processos de constituição da memória, o que remete a uma literatura copiosa. Basta lembrar o que foi dito acima sobre o esforço para apagar certos aspectos e construir a imagem de outros. Nesse sentido, é de se esperar que a memória de empregados da CVRD possa estar marcada por uma ampla elaboração.

O que se busca junto aos entrevistados não é a "verdade dos fatos" ou informações específicas, mas sim a forma como os processos de organização do trabalho foram percebidos e quais discursos foram elaborados sobre eles na época - e não posteriormente. Para tanto, é necessário estabelecer uma diferença entre os aspectos pessoais, privados da memória, e seus componentes coletivos.

5 As entrevistas fazem parte do projeto de pesquisa A greve de 1948 na Companhia Vale do Rio Doce, desenvolvida desenvolvido no Departamento de História da UFES, e podem ser obtidas pelo e-mail andre.r.pereira@ufes.br. 
Esse ponto remete ao paralelo que Ecléa Bosi (1987) estabelece entre as concepções de Henri Bergson e Maurice Halbwachs. Uma parte da memória se deve à forma como o indivíduo lida com a indeterminação do mundo e dá sentido à sua existência no presente. Outra parte possui componentes de discursos e leituras mais amplas; são referências oriundas dos grupos nos quais a pessoa se insere e constrói sua identidade ao longo da vida - sendo que essa identidade pode mudar ao longo do tempo. Algumas pessoas possuem uma memória mais "bergsoniana", enquanto outras são mais "halbwachianas”. Muitas vezes, há uma combinação dos dois elementos. Assim durante a entrevista, é importante que o entrevistador consiga perceber, no momento em que as respostas são dadas, qual o tipo predominante de leitura que está sendo oferecida; que desconfie, por exemplo, da incorporação acrítica de discursos de época. Adiante, um exemplo será utilizado, quando o entrevistado afirma que os empregados da empresa não solicitavam aumento de salários. Nesse caso, o que ele fez foi reproduzir o tipo de atitude que a gerência da empresa esperava dos seus trabalhadores e não a prática efetiva - perceptível por meio de documentos internos arquivados no Museu Vale -, nem a forma como essa regra informal era percebida.

Eu entendo que a melhor maneira de compreender o tipo predominante de memória elaborada pelo entrevistado é iniciar a entrevista com o recurso à técnica da história de vida. Ao acompanhar a trajetória de vida da pessoa, é possível conhecer a formação de seu perfil e as suas formas de inserção nas coletividades das quais fez parte. Antes disso, a pré-entrevista ou a recolha de informações sobre o entrevistado é um recurso conveniente para conhecer a sua biografia, ou seja, o que houve antes, durante e depois do período de foco da pesquisa. A combinação desses elementos oferece ao pesquisador meios para fazer uma classificação do tipo de memória elaborada pelo entrevistado. Afinal de contas, uma parte do que as pessoas contam sobre o passado se deve não só às suas experiências de infância e juventude como também ao que houve após o período que interessa para o estudo.

Tendo percebido um padrão na narrativa entrevistado, pode-se compreender a natureza das respostas que oferece e, a seguir, após as perguntas gerais, introduzir questionamentos específicos que o estimulem a ultrapassar a barreira da memória construída e evocar as lembranças de época. Nesse caso, o que interessa são as formas utilizadas pelo entrevistado e pelas pessoas com as quais conviveu de entendimento dos processos que estavam em curso. Portanto, quando falo de uma "história de vida direcionada para hipóteses 
específicas a partir do ponto em que o curso da vida do indivíduo passa a tocar no objeto de pesquisa”, me refiro a: a) iniciar a entrevista na infância; considerar b) o período escolar, c) a entrada no mercado de trabalho, d) as experiências que o entrevistado possa ter tido na arena pública (sindicalismo, eleições, militância política, religiosa etc.); e) ingressar no período que interessa para a pesquisa, buscando então captar as percepções de época.

Seguindo a pista de Bergson apresentado por Bosi, a técnica básica para atingir o objetivo é a de, percebendo que um entendimento do passado oferecido como resposta é memória construída, fazer perguntas que estimulem o entrevistado a se colocar naquele momento histórico, estimulando suas lembranças por associação. Para tanto, é importante que o entrevistador tenha um bom conhecimento empírico dos fatos e processos antes da entrevista e que explore os trechos da fala nos quais eles são apresentados. Quando os entrevistados fazem generalizações sem referência a acontecimentos específicos de época, por exemplo, é possível desconfiar que não se trate de uma "lembrança". Versando tais generalizações sobre um ponto importante para comprovar hipóteses, torna-se conveniente introduzir uma pergunta que estimule o entrevistado a se colocar no momento. Para tanto, a referência a fatos e pessoas com as quais conviveu torna-se valorosa.

Por fim, a análise da entrevista assim obtida segue o seguinte procedimento: a) recuperar a trajetória de vida: para conhecer o entrevistado, seu perfil e formas de inserção social; b) classificar o seu tipo de memória predominante: para entender que elementos oferece em termos de interpretação do passado; c) recortar a entrevista por temas e tratá-los tendo em vista as hipóteses e o que foi possível obter com a entrevista, tentando separar os aspectos pessoais e idiossincráticos das percepções conjunturais, das influências estruturais mais amplas (sobre as quais os indivíduos refletem e fazem opções) e da memória construída a posteriori. É isso que se segue.

\section{Trajetória de vida}

O senhor Juventino ${ }^{6}$ nasceu em 1914, em Santa Teresa, no interior do Espírito Santo. Seu pai era comerciante de café e agricultor, sua mãe cuidava da casa. Quando contava oito anos, a mãe faleceu; o pai não casou de novo.

6 Pseudônimo adotado a pedido do entrevistado (97 anos). 
Foi alfabetizado e aprendeu as operações matemáticas básicas. Por volta de 1927, aos 13 anos, fugiu de casa pela primeira vez. Aos 15 anos, fugiu de novo, indo morar em Vitória. Na capital, foi trabalhar em um boteco. Frequentou um curso de datilografia que consumiu todo o seu ordenado. Posteriormente, obteve incorporação como voluntário no Exército. Ele pretendia seguir a carreira militar, mas foi dispensado em 1937, em decorrência de uma decisão de âmbito nacional, que afastou da instituição os suboficiais com menos de dez anos de serviço. Devido ao seu conhecimento de datilografia, fez um teste e foi contratado para trabalhar na Estrada de Ferro Vitória-Minas - essa empresa, em 1942, seria incorporada à Companhia Vale do Rio Doce. Algum tempo depois, Juventino teve uma ideia que melhorou bastante o fluxo e o controle dos documentos da empresa. Aparentemente, por conta disso, foi designado para um cargo de chefia.

Em 1949, prestou o exame que permitia obter o certificado de licença ginasial (madureza). Contava então 35 anos, era casado, tinha uma filha e uma posição de chefia na empresa. Entre 1950 e 1952, frequentou o científico em curso noturno particular. Em seguida, passou no vestibular para a Faculdade de Odontologia do Espírito Santo, mantida pelo governo do estado. O curso foi frequentado de manhã - o horário de trabalho ia das $11 \mathrm{~h} 30$ até às $17 \mathrm{~h}$. Juventino concluiu o curso superior em 1955, aos 41 anos de idade.

Por sua sugestão, a CVRD adquiriu um gabinete dentário, que foi doado ao Sindicato dos Ferroviários. E o próprio Juventino foi cedido pela empresa, recebendo o seu salário com gratificação de chefia, para atuar como dentista na instituição. Dessa forma, ele saiu do escritório e foi para a sede do sindicato, na qual trabalhava no horário da manhã. Posteriormente, montou um consultório particular nas proximidades, onde atuava à tarde. Desse momento em diante, o entrevistado viveu grande ascensão social.

\section{Tipo de memória do entrevistado}

A trajetória de vida do entrevistado é marcada pela morte da mãe. Como seu pai não se casou de novo e assumiu uma postura agressiva no relacionamento com o filho, o resultado foi o afastamento com relação ao genitor. Por essa razão, Juventino planejou a saída de casa. A fuga e a busca de novos horizontes caracterizam sua atitude perante a vida e o tipo de memória que desenvolveu. Assim, devido ao seu perfil e a uma integração difícil no núcleo 
familiar, o entrevistado tornou-se uma pessoa voltada para seus interesses privados. Dessa forma, seus laços com grupos maiores sempre foram mediados pelos objetivos pessoais de bem-estar e ascensão social. Sua entrada no Exército teve esse sentido, já que ele não demonstrou paixão pela vida castrense. A mesma atitude se repetiria na trajetória do entrevistado na EFVM, depois CVRD. Durante toda a entrevista, ele demonstrou muito pouco interesse pela empresa em si e pelos colegas. Juventino fez um grande esforço pessoal para melhorar sua educação e obteve a recompensa devida. É desse ponto de vista que ele observa o passado. Sua leitura do mundo, portanto, é mais "bergsoniana”, o que não impede a concorrência de aspectos "halbwachianos", ou seja, da incorporação de interpretações coletivas. É na relação entre os dois aspectos que sua entrevista deve ser pensada.

\section{Análise da entrevista}

A entrevista em questão será abordada a partir de aspectos da fala de Juventino que são interessantes para lançar pistas sobre o período abordado. Assim, os pontos são: a) a herança recebida pelos empregados da CVRD na sua compreensão sobre os direitos trabalhistas dos ferroviários; b) modernidade e tradição na relação entre gerência e empregados; c) a imagem da empresa: chefes, empregados e a greve de 1948.

\section{Direitos trabalhistas dos ferroviários}

Juventino foi contratado pela Estrada de Ferro Vitória-Minas, empresa da Itabira Iron Ore Company, em 9 de julho de 1937. Com o objetivo de recuperar o seu conhecimento sobre os direitos trabalhistas, fiz uma pergunta bem específica:

Pergunta: Naquela época, para entrar na Estrada de Ferro, a pessoa tinha que ter a carteira de trabalho?

J: Não. A CLT não existia. [No caso do] horário, não havia respeito para com o trabalhador. Eu vou contar um caso. Trabalhava-se mais que 8 horas, sem receber o extraordinário. Cinco trabalhadores do almoxarifado fizeram uma brincadeira: colocaram um cartaz nas costas com impropérios e 
coisas assim. E o almoxarife não gostou daquilo. Ele se chamava Eufrásio Silva. Ele foi deputado mais tarde. Botou os cinco para fora, sem mais nem menos. Não se garantia nada. Logo depois que eu entrei, aí apareceu a Lei [CLT]. Dali a dois anos veio a estabilidade. Era assim: quem atingisse dez anos, daí para frente ficava garantido. Até nove anos, estava pendurado. (Juventino, 2012). ${ }^{7}$

A carteira de trabalho foi criada em 1932. A experiência de Juventino anterior à entrada na empresa foi no Exército, que, por razões óbvias, não exigia o documento. Não caberia uma pergunta formal do tipo: "O que o senhor sabia sobre os direitos trabalhistas?”; daí a escolha de um elemento material (a carteira) para estimular a lembrança. A resposta, porém, é bem interessante: ele associa a carteira de trabalho com a Consolidação das Leis do Trabalho (CLT), que foi editada em 1943. Por vezes, Juventino se refere à CLT apenas como "a Lei". Nesse sentido, a sua memória funciona como a de vários trabalhadores brasileiros, que atribuíram às leis trabalhistas do período, corporificadas na CLT, um poder simbólico superior ao seu real impacto na realidade. Fenômeno semelhante pode ser observado nas entrevistas feitas por Ecléa Bosi (1987).

Vale lembrar que Juventino, posteriormente, viria a experimentar uma grande ascensão social, passando a atuar, na prática, como profissional liberal, cumprindo horário no Sindicato dos Ferroviários como dentista e mantendo, ao mesmo tempo, consultório privado. Nesse sentido, mesmo tendo mudado de classe social, ele se manteve fiel à versão estabelecida ao longo do tempo segundo a qual não havia nada antes da CLT. Essa alteração de status junto com a permanência da memória construída mostra a força dessa memória como fenômeno social, no geral, e como discurso presente no ambiente da CVRD, em particular.

Como funcionário do escritório, tendo lidado com uma enorme variedade de documentos internos que tocavam no tema dos direitos trabalhistas, Juventino demonstrou autêntico desconhecimento ou desinteresse pelas conquistas anteriores à sua contratação. Como ele citou especificamente a estabilidade no emprego aos dez anos de serviço, é importante saber que a Lei Elói Chaves, de 1923, garantiu esse benefício para os empregados de estradas

7 Todas as falas reproduzidas neste texto provêm dessa fonte. 
de ferro. Em 1926, o mesmo direito foi estendido para marítimos e portuários. Em 1930, atingiu os trabalhadores de transporte urbano, luz, telefone, telégrafo, portos, água e esgoto. No Espírito Santo, na época, havia linhas férreas, uma empresa concessionária de serviços urbanos e uma movimentação portuária significativa. Ou seja, em tese, muitos trabalhadores estavam em condiçóes de serem atingidos pela medida, dando a esse direito um grau razoável de publicidade. Adiante, em 1932, a estabilidade foi estendida à mineração. Em 1934, aos bancários. Em 1935, a Lei no 62 (art. 10) reconheceu a garantia para os trabalhadores em geral. A Constituição de 1937 (art. 137, f), promulgada pouco depois da contratação de Juventino na EFVM, cita o direito. Por fim, a CLT, em 1943, no artigo 492, retomou o dispositivo (Diniz, 2006).

O entrevistado, apesar de trabalhar numa ferrovia, com o direito à estabilidade garantido desde 1923, só reconhece efetividade para o mecanismo com a CLT. Além desse, vários dispositivos legais garantiam benefícios que Juventino simplesmente desconhece, apesar de ele ter elaborado uma reflexão sobre o tema, reforçada pela introdução de um episódio comprobatório (que trata da demissão dos colegas). Há uma grande diferença entre uma leitura do passado que é feita de maneira vaga e outra que é sustentada por um episódio comprobatório - que serve, para o entrevistado, como prova empírica da tese que está defendendo (Não havia direitos, tanto que tais colegas foram demitidos sumariamente). Para estimular suas lembranças de época, fiz outras perguntas específicas:

Pergunta: E o regime de trabalho dentro da Estrada de Ferro não respeitava o horário de trabalho?

J: Quem trabalhava no escritório trabalhava 6 horas. Era até bom, viu? Mas, se precisasse trabalhar mais...

Pergunta: E não pagava hora extra?

$\mathrm{J}$ : Não pagava extra.

Pergunta: E podia demitir por qualquer razão, não é?

$\mathrm{J}$ : Depois que apareceu essa lei, não. Depois que a Lei veio, teve que pagar extraordinário, tudo direitinho.

É possível que o entendimento do entrevistado se deva ao simples fato de que, na fase em que a empresa foi privada, os direitos trabalhistas não eram respeitados, enquanto a CVRD, por ser estatal e importante no modelo de 
industrialização, pode ter sido submetida a um regime de maior vigilância. Afinal de contas, Juventino insiste no fato de que as regras passaram a ter vigência após o advento da "Lei”. Sendo essa hipótese plausível, cabe notar que a leitura dos documentos internos da Vale indicam que havia grande conflito entre a empresa e seus trabalhadores no que se refere ao cumprimento das regras legais. Diversas vezes, por exemplo, a Justiça do Trabalho foi acionada pelos empregados e dirigiu expedientes à CVRD, solicitando informações variadas. Portanto, a idealização da CLT e sua suposta efetividade na estatal faz parte muito mais da memória construída, um fenômeno social de amplas proporções, do que de outra coisa qualquer.

Entretanto, o desconhecimento dos direitos anteriores e o estabelecimento de um marco simbólico no período do Estado Novo - que, mesmo idealizado pelo entrevistado, tornou-se fonte real de dissensões entre os empregados e a Vale -, devem ser vistos como uma genuína leitura de época. Ou seja, a ignorância das leis criadas a partir de 1923 não impediu a disseminação de um conhecimento amplo das leis trabalhistas na década de 1940 e o seu uso como instrumento para a luta por melhores condições de trabalho - um esquecimento mais uma lembrança servindo para uma tomada de atitude. Logo, nem sempre as mistificações impedem a percepção do conflito e o seu enfrentamento de alguma forma.

\section{Modernidade e tradição na Vale}

Uma das fontes primárias mais importantes para estudar os anos iniciais da CVRD, com foco na relação entre a gerência e os trabalhadores da empresa, é justamente o tipo de documento que Juventino manipulava. A leitura dessa série mostra um conflito latente e constante entre os chefes e os empregados. Um aspecto que se destaca são os frequentes pedidos, dos mais variados tipos, que empregados, seus familiares e pessoas de fora da CVRD faziam por escrito.

No caso dos trabalhadores, as reclamações por atraso de salários, descontos, indenizações por acidentes, conflitos com chefias imediatas e outros pontos semelhantes saltam aos olhos. Em alguns casos, eles eram vazados em termos modernos, baseados em argumentos racionais, impessoais e profissionais. Um exemplo é o de um empregado que afirmava ter feito um curso e, por isso, solicitava seu deslocamento para uma área da empresa na qual suas 
novas habilidades tivessem uso. Ao mesmo tempo, porém, havia argumentações tradicionais, como o pedido de aumento de salário por antiguidade, por fidelidade à empresa, por respeito aos chefes. Vale notar que as respostas da gerência a tais pedidos guardavam dualidade semelhante. A mesma autoridade podia tratar uma demanda em termos modernos para, no documento seguinte, usar argumentos tradicionais a fim de tomar uma decisão.

A questão que se coloca é: por que tanto chefes como empregados oscilavam entre os dois tipos de comportamento? É preciso destacar que devido à natureza do projeto que criou a CVRD, ela deveria ser gerida em termos modernos, impessoais, profissionais, orientada para objetivos materiais claros, bem-estabelecidos. Por isso, a gerência deveria impor aos empregados um ritmo e uma rotina de trabalho que rompessem com formas arcaicas de relação entre patrão e empregado. Até certo ponto, isso foi feito, porém não completamente, e nem sempre a iniciativa foi dos chefes.

O que está em jogo é o processo de modernização. Quanto a esse ponto, há uma tradição interpretativa que enfatiza os aspectos tradicionais do comportamento dos trabalhadores (Rodrigues, 1966; Lopes, 1967) e outra que aborda a capacidade de adaptação do proletariado à modernidade (Negro, 2004; Fontes, 2008). Neste trabalho, emprego um argumento que a historiografia crítica do populismo utilizou (Ferreira, 2001), que considera a interação entre moderno e tradicional e a capacidade dos "de baixo" de agir num espaço de possibilidades. Para demonstrá-lo, vou partir das condições concretas.

Seria de se esperar que a gerência, cujos cargos mais importantes eram ocupados por engenheiros - portanto, profissionais com formação técnica -, assumisse a tarefa de implantar as reformas modernizantes na rotina da firma. Antes de converter-se em Vale, a empresa geriu uma estrada de ferro que funcionou por vários anos, perfeitamente integrada à sociedade agrário-exportadora baseada na economia do café e socialmente dominada pela lógica do coronelismo. Assim, é de se supor que as relações internas entre empregados e chefias fossem mediadas por comportamentos e atitudes tradicionais. Os novos chefes, por sua vez, teriam que romper com esta lógica, mas nem sempre o fizeram. Não se estabeleceu uma dualidade entre gerência moderna e empregados com comportamento tradicional. O problema, então, é explicar por que a coisa se deu dessa forma.

Uma hipótese geral é a de que todas as pessoas estavam submetidas a uma forma tradicional de compreensão da realidade, uma mentalidade 
característica da sociedade agrário-exportadora que ainda era dominante. Nos anos 1940, a CVRD era a principal empresa capitalista do Espírito Santo; estava, porém, inserida em uma lógica mais ampla, que demoraria em ser alterada. Além do mais, como as transformações econômicas tendem a ser mais rápidas que as mentais, culturais ou ideológicas, estaria, dessa forma, explicada a dualidade - comportamentos modernos exigidos pelas circunstâncias convivendo com atitudes tradicionais, de transformação mais lenta.

Há, todavia, dois problemas na interpretação acima. O primeiro está no fato de que, pelas circunstâncias, as pressões por uma atitude moderna seriam exercidas de forma mais intensa sobre a gerência que sobre os empregados. $\mathrm{Na}$ documentação, porém, os dois grupos apresentam atitudes igualmente variadas. $\mathrm{O}$ segundo problema é que, estando correta a hipótese de uma mentalidade tradicional associada a uma sociedade em mudança, seria de se esperar, após algum tempo, uma transformação completa de práticas tradicionais, tanto no interior quanto fora da empresa. Não parece ter sido esta a trajetória na CVRD e muito menos no Espírito Santo como um todo.

Assim, outras possibilidades devem ser exploradas. Uma delas é a do uso seletivo de argumentos e atitudes tradicionais dentro da empresa com o propósito de disciplinarização da mão de obra. De fato, a gerência combinava mecanismos tradicionais com modernos, de forma aleatória. Isso se deveu ao fato de que, nos anos 1940, o Partido Comunista do Brasil (PCB) se organizou dentro da Vale e mobilizou seus empregados numa série de lutas que culminaram com uma grande greve em 1948. Na ocasião, o PCB lutou por aumento salarial e melhorias gerais para todos os trabalhadores, baseada em noções de solidariedade horizontal, de ação coletiva coordenada e com critérios impessoais, o que caracteriza tal experiência como moderna.

A repressão ao partido na empresa foi enorme, o que implicou também uma negativa à legitimidade de um comportamento autônomo e reivindicativo vindo dos próprios trabalhadores. Ou seja, essa via foi fechada pela repressão, que eliminou a possibilidade de que um caminho exclusivamente moderno se transformasse no meio dominante de relação entre capital e trabalho no seio da empresa. Assim, usar seletivamente estímulos tradicionais para dividir os empregados e garantir solidariedade vertical (DaMatta, 1979) com a empresa se transformou numa estratégia de poder usada pela gerência, que não podia, porém, dar-se o luxo de abrir mão completamente de atitudes modernas. 
É preciso notar, porém, que não deve ser descartada, por sua vez, a hipótese de que vários trabalhadores manipulassem o discurso dos dominantes, procurando adaptá-lo aos seus interesses, na linha de abordagem desenvolvida por Sidney Chalhoub (1990) e E. P. Thompson (1987). Ou seja, tendo em vista o fracasso de uma estratégia de risco, que levou à repressão, muitos empregados optaram por buscar um contato direto, solicitando benefícios pessoais em troca de declarações de fidelidade e submissão à empresa e seus dirigentes. Com isso, pode-se inferir uma via de mão dupla, pela qual os dois lados mobilizaram estratégias que se reforçaram.

Porém, é importante destacar que a atitude moderna também estava disponível no espaço de escolhas das quais os empregados dispunham, e ela foi usada por alguns dos trabalhadores. $O$ fato de assim ter sido é relevante porque enfraquece a concepção de que os mais pobres estariam condenados a uma postura "atrasada", diagnóstico típico de uma leitura conservadora sobre a natureza dos "de baixo".

A entrevista feita com Juventino ajuda a lidar com as hipóteses aventadas. Quando o questionei sobre sua proximidade com os ferroviários, ele se recordou que um dos trabalhadores da oficina de carpintaria lhe deu uma vez um cabo de machado de presente, como retribuição por ele ter elaborado requerimentos ou outros documentos para o carpinteiro em questão. O episódio demonstrou que muitos dos documentos internos que traziam reivindicaçóes dos empregados a seus superiores não eram, necessariamente, escritos por eles. Era possível que colegas do escritório ou mesmo pessoas de outros ambientes redigissem tais textos. Num primeiro momento, indagado sobre o assunto, Juventino afirmou que as demandas dos empregados eram feitas ao chefe imediato, oralmente. Logo depois, contudo, ele afirmou que escrevia requerimentos para colegas.

Interrogado sobre se os trabalhadores sabiam ler e escrever, Juventino disse que muitos sabiam, e aí surpreendeu, afirmando que até ele havia feito um pedido verbal de aumento. A afirmativa foi espantosa, porque antes ele havia afirmado que, quando o trabalhador precisava de aumento, ficava esperando. Ele mesmo nunca havia participado de greve e nunca havia pedido aumento - quando saía, segundo Juventino, era por merecimento pessoal. Contudo, contrariando o que dissera antes, observou:

J: Quando eu trabalhava no almoxarifado, ao invés de pedir [aumento] ao almoxarife - eu achei que não iria resolver -, pedi diretamente ao Dr. 
Araripe, que morava numa chácara lá em Porto Velho. Tinha uma chácara da superintendência em Porto Velho. Eu saí e fui na casa dele pedir aumento.

Pergunta: Então era comum o empregado procurar o chefe, como o senhor fez?

J: Não, aí não. Eu me arrisquei um pouco. O superintendente morava ali, a uns 800 metros. Subi lá... Ele era uma boa pessoa, o Dr. Araripe. O que me entusiasmou foi isso, saber que ele era uma boa pessoa.

De início, Juventino negou que os trabalhadores solicitassem aumentos - ficavam numa postura passiva, esperando o reconhecimento -, e se incluiu nisso. Posteriormente, ao afirmar que os pedidos eram feitos oralmente, todavia, deu um exemplo pessoal de reivindicação laboral. Em seguida, generalizou para todos os empregados a negativa de que procurassem os chefes superiores aos seus imediatos. Ele mesmo só teria se arriscado pelo fato do superintendente Alencar Araripe ser tido por ele como "boa pessoa", o que remete à ideia de afabilidade, de uma pessoalidade que poderia ser explorada pelo trabalhador de forma direta, numa lógica de solidariedade vertical. Sua estratégia deu certo, pois cerca de três meses depois, ele recebeu o aumento.

Assim, é preciso ter em mente que mecanismos personalistas de reivindicação existiam. Há vários documentos escritos nos quais os empregados faziam pedidos; pela entrevista, nota-se que eles conviviam com conversas informais. O próprio Juventino redigiu requerimentos para colegas, mas demonstrou pouca atenção para o que eles significavam. Isso é relevante porque, como funcionário do escritório, ele lidava com a movimentação dos processos, e deveria ter tido clareza da importância de tais pedidos, que, com certeza, passavam por suas mãos; afinal, ele era responsável por sua classificação.

Ocorre que o entrevistado não estava atento para a realidade dos colegas. Mesmo assim, foi possível recuperar a prática do contato pessoal e o cálculo que incluía uma tentativa de manipular o discurso do dominante. Afinal de contas, como princípio geral, Juventino expressou, de início, a "regra” de que não se pedia nada e se esperava pelo reconhecimento. Que essa não era a prática fica claro tanto na documentação escrita quanto na própria entrevista. $\mathrm{O}$ que o entrevistado expressou foi um discurso, uma leitura da realidade, aquilo que a gerência esperava dos trabalhadores, numa linha bem tradicional: silêncio, fidelidade e recompensa para quem merecesse. $\mathrm{O}$ entrevistado tinha clareza de tal "regra" não escrita, mas não se submeteu a ela. Foi reivindicar e, 
provavelmente, na conversa com o superintendente (passando por cima do seu chefe direto no almoxarifado), sendo conhecedor dos meandros da fala dos dominantes, expressou-se em termos que o convenceram.

O episódio pode ser tomado como ilustrativo da atitude que muitos empregados tiveram, na medida em que manipulavam o discurso dos dominantes como estratégia para enfrentar as dificuldades em que viviam. Foi algo pensado dentro de uma estrutura de possibilidades, e não um simples comportamento aprendido e repetido de forma mecânica, sem reflexão. Vale notar que o entrevistado não enxergava a ação coletiva com base em critérios universalistas como caminho para as reivindicações. Diante dessa percepção da realidade, suas reivindicações seriam sempre feitas pela via individual, fossem com base em argumentos tradicionais ou modernos. E Juventino fez uso de ambos, cada um a seu tempo, conforme as possibilidades, o que revela o cálculo.

O perfil do entrevistado mostra que ele buscou manipular meios modernos para obter ascensão social. Usou o Exército como via de crescimento profissional. Dentro da Vale, usou seu intelecto para solucionar um problema administrativo que lhe valeu o reconhecimento, do qual resultou um cargo de chefia. Ele queria mais e continuou na linha da formação profissional. Diplomado, fez um acordo com a empresa em termos puramente racionais: a instalação de um gabinete dentário no sindicato para prestar serviços aos empregados (o que fazia parte de uma estratégia de prestação de serviços via sindicato com o objetivo de despolitizá-lo) e sua transferência para tal atividade (mantendo o salário que recebia) - a empresa seria beneficiada e ele também. Toda essa trajetória é moderna e muito coerente com o perfil e as atitudes do entrevistado ao longo da vida. Ele seria, portanto, exemplo de uma pessoa moderna numa sociedade tradicional. Seria uma aparente exceção que, contudo, não deve ser levada muito a sério, pois documentos da empresa demonstram que, na mesma época, vários de seus colegas se expressavam em termos semelhantes, justificando suas reivindicações com argumentos racionais, profissionais e como resultado de formação educacional.

Ocorre que, em outro momento, Juventino foi perfeitamente capaz de usar meios tradicionais para atingir seus objetivos. Se um indivíduo com esse perfil não teve embaraços para navegar em diferentes mares, por que os colegas também não o fariam? Dessa forma, os termos moderno e tradicional se referem a padrões de relações sociais que não eram estanques, plenamente separados e convivendo de forma desconfortável, como expressões de formas 
históricas distintas, com uma tendendo a vencer e outra a desaparecer. Exprimem, antes, modelos que estavam disponíveis para os atores no interior de um espaço de probabilidades que, por conta da repressão à ação coletiva autônoma, ficou mais estreito (Przeworski, 1989).

Da sociedade tradicional em que a Vale estava inserida, seus funcionários - tanto gerentes quanto trabalhadores - herdaram padróes de comportamento, que levaram para o interior da empresa (aspectos estruturais). Todavia, as pessoas não são vítimas de condicionantes maiores; eles funcionam como estímulos, a que se pode responder ou não. Na conjuntura da década de 1940, a industrialização pesada foi imposta pelo Estado como projeto para o país - no caso da CVRD, implicava formas de ação coletiva modernas. Para tanto, era necessário disciplinarizar os empregados, o que sempre se coloca como tarefa inevitável em fases de transição para o capitalismo (Polanyi, 1980). Todavia, o perigo representado pelo PCB levou a uma atitude repressiva. A gerência buscou, então, canalizar as demandas para o plano puramente individual, tentando dividir os empregados com o uso seletivo de argumentos modernos e tradicionais. Estes últimos permitiam estimular a solidariedade vertical, o contato direto entre superior e inferior, enfraquecendo, portanto, os laços horizontais, que são típicos da modernidade. Ao mesmo tempo, porém, os empregados não foram de todo passivos. Fechado o caminho da ação coletiva autônoma, passaram a manipular o discurso dos dominantes, seja nos termos modernos, seja nos tradicionais. Isso fica bem claro no tipo de atitude assumida por Juventino: foram escolhas feitas no plano das conjunturas, como resultado da ação humana reflexa, diante de circunstâncias condicionantes - é isso que explica a combinação de modernidade e tradição. A interação entre os dois aspectos é marcante para entender a história da empresa, do Espírito Santo e do Brasil.

\section{A imagem da empresa}

A memória sobre a Vale produziu uma imagem da empresa. Sobre isso, tomarei o caso de Eliezer Batista, presidente da empresa em dois momentos diferentes (1961-64 e 1979-86), cuja figura sofreu um processo de mitificação que personificou as supostas qualidades da empresa. Isso aparece na entrevista com Juventino, quando, indagado sobre a presença de americanos na CVRD nos anos 1940, disse: 
Pergunta: Quanto tempo os americanos ficaram trabalhando?

J: Três ou quatro anos retificando. O Eliezer Batista, que é pai do Eike Batista, ele entrou na Estrada, na Vale, trabalhando na primeira residência, lá em Minas Gerais. Residência é um trecho da linha. E ele é trabalhador. Até ajudava os socadores de pedra nos trilhos. Ele ia até ajudar. Como engenheiro, ele fazia isso. Depois ele veio a ser superintendente da Vale e até presidente. E produziu o Eike Batista, que é um grande milionário.

É significativo que Juventino tenha associado, de forma espontânea, a figura de Batista a engenheiros americanos, que entraram na CVRD em 1943 com a função de retificar a linha da estrada de ferro e realizar outras obras. Os americanos eram tidos como superiores, e Batista entra na sequência da resposta. Para o entrevistado, seu grande mérito foi o de ter sido "trabalhador"; a prova de sua competência foi o filho que gerou. Várias outras fontes destacam-no de forma positiva. Já o jornal Folha Capixaba, do PCB/ES, em 1956, publicou que sua esposa estaria expulsando trabalhadores e aposentados do Morro da Companhia, onde o casal havia se instalado (Vale expulsa trabalhadores, 1956). Em minhas leituras, nunca havia visto referência negativa sobre Batista. Não está em causa aqui a veracidade da acusação do jornal, mas a simples caracterização do indivíduo em questão com uma roupagem negativa - essa possibilidade de leitura foi eliminada pelo projeto de poder vencedor. Nesse aspecto, Juventino, ao que parece, incorporou a fala dominante, mitificadora. Para verificar o alcance dessa leitura, fiz perguntas sobre outras pessoas que ocuparam cargos de chefia.

Sobre o primeiro presidente da CVRD, Israel Pinheiro, o entrevistado lembrou que ele "metia a mão no bolso [e] tirava um monte de dinheiro", por ser "cheio da gaita", enquanto os colegas eram pobres. Acerca de Demerval Pimenta, cunhado de Pinheiro e segundo presidente, Juventino pôde apenas informar que, quando ele e os diretores vinham do Rio para Vitória, usavam um trem especial, "com muita mordomia”. Sobre esse ponto específico, é possível encontrar uma série de artigos bastante críticos, publicados no jornal A Gazeta em 1947-48 pelo seu editor-chefe, Eurico Rezende, denunciando uma série de desmandos e benefícios indevidos para a diretoria da empresa. Portanto, esse é outro exemplo empírico que alcançou um grau razoável de conhecimento. Informações desse tipo poderiam ter alimentado uma memória crítica, que questionasse procedimentos e relações de poder na empresa elas estavam disponíveis até para uma pessoa desinteressada em política como 
Juventino. Interrogado especificamente sobre o tema, ele foi capaz de oferecer elementos, mas que não foram articulados em uma interpretação ampla que pudesse questionar a fala vencedora.

Sobre outros chefes, o entrevistado seguiu no padrão anterior. O superintendente da Estrada de Ferro (cargo mais alto em Vitória) Itagiba Escobar, por exemplo, foi tido por ele como "terrível", por ser inflexível na disciplina. Já João Carlos Beleza, que ocupou o mesmo posto, tinha um "coração de mãe", era "amigo do trabalhador". Essa imagem contrasta fortemente com a informação que obtive em outra entrevista, com um militante do PCB, que me apresentou Beleza como um indivíduo de má índole, que costumava solicitar favores sexuais às mulheres que pediam emprego na Vale (Granja, 2012). Mais uma vez, não está em jogo a veracidade dos perfis apresentados, mas sim a descoberta de que, quando abordado sobre chefes específicos, o padrão de resposta do entrevistado foi o de se recordar de aspectos pessoais, anedóticos - que até poderiam ter alimentado uma versão mais crítica, mas não o fizeram.

Como nos diz E. P. Thompson (1989), os trabalhadores sempre têm algum tipo de percepção da experiência da exploração e do poder. A forma como respondem a isso historicamente é que possibilita ou não o advento da consciência de classe. $\mathrm{O}$ que eu percebo aqui é que houve um processo que impediu a elaboração de uma perspectiva coletiva crítica e autônoma elaborada pelos "de baixo". Eles sabiam, é claro, de vários aspectos condenáveis. Sobre o papel dos engenheiros, de uma forma geral, o entrevistado afirmou:

Pergunta: E os engenheiros tinham muitas regalias?

C: Muita, muita, muita regalia. Chegava na hora que quisesse. O Bocaiúva, por exemplo, eu me lembro. Ele morava na praia. De manhã chegava para trabalhar, depois voltava às três horas, porque ia lá para a praia tomar banho.

Mais uma vez, a resposta pode ser tida como autêntica elaboração interpretativa por conta da presença do episódio comprobatório. Ou seja, trata-se de um tema sobre o qual Juventino já havia refletido, tanto que dispunha de uma prova empírica para oferecer. O jornal Folha Capixaba, por sua vez, também criticava a postura dos engenheiros, que ocupavam quase todos os cargos de chefia. Esse assunto, entretanto, não ultrapassou a barreira do discurso oficial. 
Mais importante do que isso, porém, foi a questão do salário:

Pergunta: O salário [em 1948] era baixo?

$\mathrm{J}$ : Era baixo.

Pergunta: Não era bom trabalhar na Vale nessa época, em termos de salário?

C: Bom, depois que foi aumentando a Vale, que foi crescendo, foi melhorando, mas, no começo, o salário era baixo. Ela era herdeira da Vitória-Minas. A Vitória-Minas vivia na pendura, com subsídio do governo. Durante muitos anos, ela foi subsidiada, porque a renda dela não era suficiente.

Aqui, Juventino forneceu uma leitura que se transformou em um mito bem mais poderoso que a imagem positiva de Eliezer Batista e sua associação com o comando da empresa como um todo. Digo isso porque, na outra entrevista que citei acima, de um militante do PCB, o mesmo mecanismo explicativo foi oferecido, se bem que em termos um pouco diferentes. Mas a tese é a mesma: na medida em que a CVRD foi crescendo, os salários foram aumentando.

A análise da documentação interna da Vale mostra que o discurso de que a empresa passava por dificuldades e não tinha como melhorar os níveis salariais era recorrente nos anos 1940 e deve ter sido usado por muito tempo. Essa interpretação foi incorporada por vários setores e acabou se transformando numa versão oficial. Mesmo assim, é claro que os empregados percebiam os baixos níveis salariais e a distribuição desigual dos pagamentos. Refletiam sobre isso, mas, no final do processo, não conseguiram contraditar o discurso dominante. Isso também ocorreu com o tema dos benefícios que a empresa supostamente "concedeu" aos seus contratados. Da mesma maneira que na questão anterior, Juventino aborda o assunto de forma matizada:

Pergunta: A Vale investia alguma coisa na educação do empregado? $\mathrm{J}$ : Investia, porque ela pagava uma escola. Lá em Cariacica tinha uma escola que ela pagava. Para os filhos dos empregados. E, no tempo do Dr. Araripe e do Beleza, no Natal, dava presentes para os filhos dos empregados. Um tempo depois, cortou.

Pergunta: Para o trabalhador, não tinha muito investimento em educação? J: Para o empregado, não. Não tinha nada. 
Nesse ponto, o entrevistado se mostra equivocado quanto a alguns fatos. Houve sim investimento da empresa na educação dos empregados, além da escola para os filhos citada. A CVRD criou duas instituições de formação profissional, sendo que uma delas deu origem ao SESI (Serviço Social da Indústria) do Espírito Santo. O que interessa, porém, é a imagem elaborada. O discurso oficial afirma que houve uma gama de benefícios distribuídos, incluindo não só educação como planos facilitados de habitação e de lazer - com o estímulo a clubes de funcionários da empresa -, assim como o acesso à Caixa de Aposentadoria e Pensões da Vale, com médicos, dentistas, etc. O próprio Juventino atuou como dentista no Sindicato cedido pela CVRD. Mesmo assim, indagado sobre o tema, ele não chegou a oferecer maiores explicações sobre o que fazia. Esse aspecto do discurso dominante, portanto, não teve grande acolhida por parte do entrevistado, o que mostra o caráter seletivo não só da memória (interpretação posterior dos fatos) como da representação das relaçôes de poder no momento em que elas ocorrem. Nem sempre os "de baixo" aceitam o discurso dominante no seu todo. Podem selecionar partes dele e reproduzi-las com toques pessoais, o que fica claro no caso de Juventino. $\mathrm{O}$ relevante, porém, é em que medida os dominados - na época em que viveram os eventos ou posteriormente, quando elaboraram a memória sobre eles - são capazes de oferecer uma leitura contrária que adquira o status de um discurso (e uma prática) alternativo. A entrevista em questão mostra que isso não foi possível.

Para concluir, recupero a lembrança de Juventino sobre um momento-chave: a greve de 1948. A forma como ela foi esquecida pelo discurso vencedor e percebida pelo entrevistado fecha o quadro das relações de poder na empresa. Em primeiro lugar, o que ele alega é que a paralisação foi organizada pelo Sindicato dos Ferroviários. Essa informação não é de todo correta: a mobilização foi conduzida por uma Comissão de Salários, que atuava nos locais de trabalho e era dirigida politicamente pelo PCB; o sindicato apoiou a luta, mas não a dirigiu, até por conta do clima de repressão às entidades classistas durante o governo Dutra. Interrogado sobre a Comissão de Salário, o entrevistado disse não ter tido conhecimento dela.

Em 1948, houve duas paralisações na CVRD: a primeira ocorreu entre 20 de agosto e 6 de setembro e a segunda durou de 26 de novembro até 2 dezembro. Como resultado, a empresa pagou um aumento que começava em $40 \%$ para os salários mais baixos e seguia em escala decrescente. Ao mesmo tempo, porém, a repressão foi intensa, com 422 demissões numa primeira 
leva, seguidas de várias outras ao longo do ano de 1949. Além disso, alguns trabalhadores foram processados na justiça comum e os controles internos se intensificaram. Na segunda parede, membros do Departamento Federal de Segurança Pública, antiga Polícia do Distrito Federal, foram deslocados para Vitória. Eles criaram um clima de terror, ameaçando pessoas com prisões e torturas. O movimento foi encerrado com a intermediação do governador Carlos Lindenberg, do extinto PSD (Partido Social Democrático).

Indagado sobre a repressão à greve, Juventino disse que ela se resumiu às demissões - ele não se lembra da presença da Polícia Federal. Recordou-se de que não aderiu à greve e defendeu a tese de que o pessoal do escritório não parava. Diante disso, apresentei o nome de duas escriturarias que aderiram (a informação consta de documentação interna da empresa), mas ele não se lembrou delas. Com minha insistência, Juventino se recordou de um colega de escritório que era comunista e foi demitido, mas o nome não foi recuperado pela sua memória. Perguntei o que diziam sobre os comunistas. Resposta: "é bicho ruim".

Meu entrevistado revelou-se uma pessoa politicamente conservadora e desinteressada dos aspectos da vida pública. Por isso, as perguntas específicas demonstram que, na época, ele teve uma atitude de afastamento com relação à greve. Nesse caso, acaba não sendo um bom informante para se avaliar o peso da repressão sobre aqueles que participaram ativamente daquela experiência ou sobre os que a observaram com interesse, como um exemplo, dentro e fora da Vale, a ser seguido ou não. No que se refere a esse ponto, é preciso buscar outras fontes.

\section{Considerações finais}

O conjunto da entrevista ofereceu vários insights importantes para entender as relações de poder no interior de uma empresa tão importante para o Brasil e para o Espírito Santo. Pessoas como Juventino experimentaram diferentes formas de organização do trabalho, refletiram sobre elas e deram respostas com base em influências de longo prazo, mas sem se tornarem vítimas delas. Foram capazes de fazer um cálculo sobre as possibilidades abertas, que não foram muitas, e agiram da maneira que lhes pareceu a mais conveniente. Neste caso, especificamente, a escolha foi pela ascensão social pela dedicação aos estudos e pelo mérito pessoal no trabalho. Porém, quando 
a oportunidade surgiu, ele não deixou de agir tradicionalmente. Por fim, incorporou em sua memória vários aspectos do discurso dominante (memória "halbwachiana"), mas não sem um grau de seletividade e tons pessoais. De forma coerente com sua trajetória, lembra-se muito pouco dos mecanismos mais ativos de ação coletiva na empresa, porque não se interessou na época nem posteriormente, apesar de ter atuado durante anos na sede do Sindicato dos Ferroviários, em contato direto com os trabalhadores em seu consultório. Esse perfil de entrevistado ajuda em vários propósitos numa pesquisa como a que estou fazendo. Afinal de contas, se mesmo alguém tão desinteressado pela realidade dos colegas pode dividir várias experiências e percepções com eles, isso se deve ao fato de que todos os seres humanos estão presos aos mesmos desafios - cabe aprender com suas experiências. Por isso, o dever dos historiadores é fazer as perguntas adequadas, sem ceder às primeiras impressões, assumindo uma postura ativa perante a produção do conhecimento. Talvez por essa razão, Juventino tenha dito ao final: "Não sai mais nada. Espremeram tudo!"

\section{Referências}

ALBERTI, Verena. Manual de história oral. 2. ed. Rio de Janeiro: Editora FGV, 2004.

BOSI, Ecléa. Memória e Sociedade: lembranças de velhos. 2. ed. São Paulo: T. A. Queiroz; Edusp, 1987.

CHALHOUB, Sidney. Visões da liberdade: uma história das últimas décadas da escravidão na Corte. São Paulo: Companhia das Letras, 1990.

DAMATTA, Roberto. Carnavais, malandros e heróis: para uma sociologia do dilema brasileiro. Rio de Janeiro: Zahar, 1979.

DINIZ, Dulce. Estabilidade e garantia no emprego. Revista Eletrônica da Faculdade de Direito de Campos, Campos dos Goytacazes, v. 1, n. 1, p. 1-24, nov. 2006. Disponível em: <http://bdjur.stj.gov.br/xmlui/bitstream/handle/2011/18314/Estabilidade_e_Garantia_ no_Emprego.pdf? sequence=2>. Acesso em: $21 \mathrm{dez} .2012$.

FERREIRA, Jorge (Org.). O populismo e sua história: debate e crítica. Rio de Janeiro: Civilização Brasileira, 2001.

FERREIRA, Marieta M.; AMADO, Janaína. Apresentação. In: FERREIRA, Marieta M.; AMADO, Janaína (Orgs.). Usos \& abusos da história oral. Rio de Janeiro: Editora FGV, 1996. p. VII-XXV. 
FONTES, Paulo. Um nordeste em São Paulo: trabalhadores migrantes em São Miguel Paulista (1945-1966). São Paulo: Editora FGV, 2008.

LOPES, Juarez R. B. A crise do Brasil arcaico: estudo da mudança das relações de trabalho na sociedade patrimonialista. São Paulo: Difel, 1967.

MINAYO, Maria C. S. De ferro e flexiveis: marcas do Estado empresário e da privatização na subjetividade operária. Rio de Janeiro: Garamond, 2004.

NEGRO, Antonio L. Linhas de montagem: o industrialismo nacional-desenvolvimentista e a sindicalização dos trabalhadores. São Paulo: Boitempo, 2004.

POLANYI, Karl. A grande transformação: as origens da nossa época. Rio de Janeiro: Campus, 1980.

PRZEWORSKI, Adam. Capitalismo e social-democracia. São Paulo: Companhia das Letras, 1989.

RAMALHO, José R. Estado-patrão e luta operária: o caso da FNM. Rio de Janeiro: Paz e Terra, 1989.

RODRIGUES, Leôncio M. Conflito industrial e sindicalismo no Brasil. São Paulo: Difel, 1966.

SILVA, Marta Z. A Vale do Rio Doce na estratégia do desenvolvimento brasileiro. Vitória: EDUFES, 2004.

THOMPSON, Edward P. A formação da classe operária inglesa. Rio de Janeiro: Paz e Terra, $1987.3 \mathrm{v}$.

. Tradición, revuelta y consciencia de clase: estúdios sobre la crisis de la sociedade preindustrial. 3. ed. Barcelona: Editorial Crítica, 1989.

THOMPSON, Paul. A voz do passado: história oral. Trad. Lólio L. Oliveira. Rio de Janeiro: Paz e Terra, 1992.

VALE expulsa trabalhadores. Folha Cabixaba, Vitória, p. 1, 6 out. 1956.

\section{Fontes orais}

GRANJA, Antonio Ribeiro. Entrevista concedida a André R. V. V. Pereira para o projeto A greve de 1948 da Companhia Vale do Rio Doce, Serra, 19 jul. 2012. Disponível em: <andre.r.pereira@ufes.br>.

JUVENTINO [pseudônimo]. Entrevista concedida a André R. V. V. Pereira para o projeto A greve de 1948 da Companhia Vale do Rio Doce, Vitória, 24 fev. 2012. Disponível em: <andre.r.pereira@ufes.br>. 
Resumo: Este artigo discute o início do processo de disciplinarização da mão de obra na Companhia Vale do Rio Doce (CVRD), empresa estatal criada em 1942 - voltada para a extração, transporte e exportação de minério de ferro -, atuante entre Minas Gerais e Espírito Santo. Para tanto, recorre à análise de uma entrevista realizada com um ex-funcionário que ingressou nos seus quadros antes da estatização. A hipótese defendida é a de que houve uma combinação de repressão política com o uso alternado de formas modernas e tradicionais de relacionamento entre a gerência e os empregados. A técnica utilizada foi a da história de vida, direcionada para hipóteses específicas a partir do ponto em que o curso de vida do indivíduo passa a tocar no objeto de pesquisa. Os pontos abordados envolvem a memória sobre os direitos trabalhistas dos ferroviários, o confronto entre comportamentos tradicionais e modernos na empresa e a elaboração de uma imagem positiva da firma, que apagou as contradições no seu interior.

Palavras-chave: Companhia Vale do Rio Doce, disciplinarização, memória.

They took it all! Modernity and tradition in the memory of a former employee of Companhia Vale do Rio Doce

\begin{abstract}
This article deals with the imposition of disciplinary methods at the workplace in the Companhia Vale do Rio Doce, created in 1942 by the Brazilian Federal Government in order to extract, transport and export iron ore. This activity was conducted in the states of Minas Gerais and Espírito Santo. The main research method is an interview with a former employee that was hired before the imposition of federal government control. The hypothesis presented follows: there was a combination between political repression and the alternate use of modern and traditional ways of relationship inside the firm's hierarchy. The interview was conducted by the method of life story, introducing hypotheses as the employee's experiences begin to relate to the object of research. The topics addressed were: railroad workers' memories on legal protection measures, the clash between modern and traditional behavior inside the company and the positive image of work relations that erased contradictions at the workplace.
\end{abstract}

Keywords: Vale do Rio Doce Company, disciplinary methods at workplace, memory.

Recebido em 31/12/2012

Aprovado em 14/05/2013 